\title{
Risk Assessment of Smokeless Tobacco among Oral Precancer and Cancer Patients in Eastern Developmental Region of Nepal
}

\author{
Jyotsna Rimal ${ }^{1 *}$, Ashish Shrestha², Iccha Kumar Maharjan ${ }^{1}$, Sushmita Shrestha ${ }^{3}$, \\ Priyanka Shah ${ }^{4}$
}

\begin{abstract}
Background: Oral potentially malignant disorders (OPMDs) and oral cancer (OC) are preventable oral mucosal diseases prevalent in Asian region. This epidemiological study aims to identify oral potentially malignant disorders (OPMDs) and oral cancer (OC), confirm histopathologically, and treat or refer these cases among the population of Eastern Development Region (EDR) of Nepal. It also attempts to assess the risk factors associated in order to compare dose-response measurements of oral habits in these patients. Methods: Cross-sectional epidemiological study was conducted over a period of 2 years in 16 districts of EDR. A total of 3,200 people were screened. A brief history was taken and visual screening examination was conducted in two phases as described by British Columbia Oral Cancer Prevention Program. Suspicious oral lesions were biopsied either by punch or scalpel after toluidine blue staining. Tissue specimen was transported to the institutional lab for histopathological processing. The reports were sent to the patients through the local leaders or organizations. Results: More than $40 \%$ of the study population either chewed areca nut and/or tobacco. Eighteen percent were smokers. OPMDs were prevalent among 468 study population with male-female ratio of 3:1. Tobacco pouch keratosis (50.4\%) was the most prevalent OPMD, followed by OSF (29.1\%). Fifty-two had squamous cell carcinoma and 8 had verrucous carcinoma. Conclusion: Chewing areca nut, tobacco, commercial areca nut/tobacco preparation and smoking being the major risk factors, there is high prevalence of oral cancer and OPMDs in the EDR of Nepal.
\end{abstract}

Keywords: Epidemiology- oral potentially malignant disorders- oral cancer- risk assessment- smokeless tobacco

Asian Pac J Cancer Prev, 20 (2), 411-415

\section{Introduction}

Oral potentially malignant disorders (OPMDs) and oral cancer (OC) are associated with betel quid chewing (Rimal and Shrestha, 2015). Betel quid chewing comprises of areca nut, slaked lime, betel leaf with or without tobacco. Arecanut is the fourth most addictive substance globally and is socially acceptable habit in South Asia (Gupta and Warnakulasuriya, 2002; Balasimha and Rajagopal, 2004). Arecanut is often chewed in a form of betel quid. Generally, a betel quid comprises of arecanut, slaked lime, betel leaf with or without tobacco. Nowadays, these quids are available commercially in sachets and are popular in public due to vigorous marketing strategy of these products (Gupta and Warnakulasuriya, 2002). The incidence of OPMDs is becoming an epidemic, targeting the younger generation. These habits have been associated with lesions like leukoplakia, erythroplakia, oral submucous fibrosis (OSF), chewer's mucosa, periodontal diseases etc. ultimately may lead to OC. Many of these are preventable and curable if diagnosed early (Kerr et al., 2011). Most of the OPMDs are diagnosed on routine oral examination (Rimal and Shrestha, 2015). In Nepal, there is no epidemiological data on the prevalence of oral mucosal lesions with focus on oral precancer or cancer. Epidemiological studies have shown the relationship between OC risks and tobacco chewing among men (Madani et al., 2010; Zini et al., 2010; Yang et al., 2010). The aim of this study was to identify OPMDs and oral cancer, confirm histopathologically, treat or refer patients and also to assess the risk factors associated with oral habits.

\section{Materials and Methods}

A cross-sectional epidemiological study was carried out from October 2012 to October 2014. Approval from Institutional ethical review board (IERB) (Acad. 478/069/070) of B.P. Koirala Institute of Health Sciences, along with ethical approval from Nepal Health Research 
Council (Reg. no. 128/2012) were obtained. Pamphlets relating to oral health, tobacco use, OPMDs and OC were designed and printed for distribution. The screening camps were organized with the assistance of local clubs/ organizations/leaders like Rotary clubs and/or youth club in each district. The public were informed well ahead of time of camp through FM radio for dissemination of the information of the screening camps.

A total of 3,200 people, consisting of 200 from each district (using stratified cluster sampling) with age range of 16-70 years were screened for OPMDs and OC at the screening camps organized in 3 zones covering 16 districts of Eastern Developmental Region (EDR). Study site was designed as per WHO Oral Health Survey-Basic Methods. The study base was B.P. Koirala Institute of Health Sciences, Dharan.

Scheduling for the main study was planned on the basis of pilot study conducted on randomly selected 50 individuals of Danda Bazaar, Dhankuta during an oral health camp. The psychometric properties of the questionnaire in terms of concurrent validity as well as internal and test-retest reliability were good.

The self-administered questionnaire was used for demographic data and information regarding tobacco habits. A brief history was taken about general health history, oral hygiene habits, oral deleterious habits and symptoms of oral pain or discomfort in a pro forma. Visual screening examination was conducted as described by British Columbia Oral Cancer Prevention Program (Williams et al., 2008). Optional screening adjunct (Toluidine blue staining) was used for determining the site before the biopsy. Tissue specimen were transported to the institute's laboratory for histopathological processing. On completion of data collection, knowledge regarding oral carcinogens and their effects on the oral cavity was provided to the study population. Oral health education was provided regarding maintenance of oral hygiene and oral urgent treatments.

The histopathological reports along with referrals were sent via emails, to the local club/organization/leader for distribution to the patients. Individuals with OPMDs or OC were referred to BP Koirala Institute of Health Sciences Hospital for further management.

The data was entered in SPSS 11.5 version and analyzed by logistic analysis to determine the association between habits and lesions. Odds ratios were used to associate different habits, their frequency and duration of use with the occurrence of OC and/or OPMDs. P values of less than 0.05 were considered to be statistically significant.

\section{Results}

A total of 3200 participants, with equal gender distribution, were studied. The mean age of the population was $38.46 \pm 14.42$ with almost equal age group distribution. With regard to literacy of the population $84 \%$ could read and $88.3 \%$ could write. More than $40 \%$ of the study population either chewed areca nut and/or tobacco. Eighteen percent were smokers and less than $10 \%$ consumed some form of alcohol. Oral hygiene status of the population showed that more than $95 \%$ had stains and deposit in their teeth, almost $20 \%$ had periodontitis and nearly $30 \%$ suffered from receding gums. OPMDs were prevalent among 468 of the study population with male-female ratio of 3:1 and concentrated more in the plains. OPMDs diagnosed were tobacco pouch keratosis (TPK), leukoplakia, lichen planus, oral candidiasis and OSF. Area wise distribution showed that OPMDs were more prevalent in Morang district followed by Sunsari and Siraha. However, prevalence was also seen in hill districts namely, Taplejung, Ilam and Okhaldhunga. Solukhumbu district also showed notable number of OPMDs. Tobacco pouch keratosis $(50.4 \%)$ was the most prevalent form of OPMD followed by OSF (29.1\%). Labial vestibule, followed by floor of the mouth, were the most affected sites. Only 16 cases did not have chewing habits. Three hundred seventy-six smoked and 352 consumed alcohol.

Amongst the 3200-people surveyed, 60 of them had OC (40 males and 20 females) of which most were either in the range of 45-54 years or more than 64 years. Most of them belonged to the districts from the plains, namely Morang, Sunsari, Saptari and Jhapa. Only 4 patients of oral cancer did not chew areca nut and/or tobacco. Thirtysix of them were smokers and 16 of them consumed

Table 1. Association of Demographic Characteristics, Alcohol Habits, Oral Hygiene and Periodontal Health with OC and OPMDs $(\mathrm{n}=3,200)$

\begin{tabular}{|c|c|c|c|}
\hline Variables/Categories & $\begin{array}{c}\text { Frequencyn } \\
(\%)\end{array}$ & $\mathrm{OR}^{\mathrm{c}}$ & $95 \% \mathrm{CI}$ \\
\hline \multicolumn{4}{|l|}{ Age in years } \\
\hline$<30$ & $684(21.4)$ & 1 & - \\
\hline $30-45$ & $1,844(57.6)$ & 3.48 & $2.51-4.82$ \\
\hline$>45$ & $672(21.0)$ & 3.42 & $2.38-4.91$ \\
\hline \multicolumn{4}{|l|}{ Sex } \\
\hline Female & $1,600(50.0)$ & 1 & - \\
\hline Male & $1,600(50.0)$ & 0.3 & $0.24-0.37$ \\
\hline \multicolumn{4}{|l|}{ Alcohol } \\
\hline No & $2,872(89.8)$ & 1 & - \\
\hline Yes & $328(10.2)$ & 4.21 & $3.29-5.37$ \\
\hline \multicolumn{4}{|l|}{ Alcohol duration } \\
\hline No & $2,872(89.8)$ & 1 & - \\
\hline$\leq 20$ years & $196(6.1)$ & 5.53 & $4.09-7.46$ \\
\hline$>20$ years & $132(4.1)$ & 2.71 & $1.84-3.99$ \\
\hline \multicolumn{4}{|l|}{ Periodontal pockets } \\
\hline No & $2,588(80.9)$ & 1 & - \\
\hline Yes & $612(19.1)$ & 3.96 & $3.23-4.87$ \\
\hline \multicolumn{4}{|l|}{ Gingival recession } \\
\hline No & $2,212(69.1)$ & 1 & - \\
\hline Yes & 988 (30.9) & 9.72 & $7.83-12.06$ \\
\hline \multicolumn{4}{|l|}{ Oral hygiene } \\
\hline Good & $464(14.5)$ & 1 & - \\
\hline Fair & $1,684(52.6)$ & 2.85 & $2.01-4.47$ \\
\hline Poor & $1,052(32.9)$ & 7.5 & $3.12-9.47$ \\
\hline
\end{tabular}

Statistical significance, $\mathrm{p}<0.20$; OR: Crude odds ratio; $95 \%$ CI: $95 \%$ confidence interval 
Table 2. Association of Arecanut, Smokeless Tobacco and Smoking Habits with OC and OPMDs $(\mathrm{n}=3,200)$

\begin{tabular}{|c|c|c|c|}
\hline Variables/ Categories & $\begin{array}{c}\text { Frequency } \\
\mathrm{n}(\%)\end{array}$ & $\mathrm{OR}^{\mathrm{c}}$ & $95 \% \mathrm{CI}$ \\
\hline \multicolumn{4}{|l|}{ Chewing habit } \\
\hline No & $1,884(58.8)$ & 1 & - \\
\hline Arecanut & $772(24.2)$ & 5.23 & $3.09-8.28$ \\
\hline Tobacco & $544(17.0)$ & 6.24 & $4.67-10.64$ \\
\hline \multicolumn{4}{|l|}{ Arecanut } \\
\hline No & $2,472(77.2)$ & 1 & - \\
\hline Yes & $728(32.8)$ & 2.47 & $2.02-3.02$ \\
\hline \multicolumn{4}{|l|}{ Arecanut + betel leaf } \\
\hline No & $2,944(92.0)$ & 1 & - \\
\hline Yes & $256(8.0)$ & 6.36 & $4.87-8.30$ \\
\hline \multicolumn{4}{|c|}{ Arecanut + betel leaf + lime } \\
\hline No & $2,976(93.0)$ & 1 & - \\
\hline Yes & $224(7.0)$ & 7.36 & $5.47-9.63$ \\
\hline \multicolumn{4}{|c|}{ Arecanut + betel leaf + lime + catechu } \\
\hline No & $2,996(93.6)$ & 1 & - \\
\hline Yes & $204(6.4)$ & 5.27 & $3.93-7.07$ \\
\hline \multicolumn{4}{|c|}{ Arecanut + betel leaf + lime + catechu + tobacco } \\
\hline No & $3,024(94.5)$ & 1 & - \\
\hline Yes & $176(5.5)$ & 10.97 & $7.93-15.17$ \\
\hline \multicolumn{4}{|c|}{ Commercial tobacco preparation } \\
\hline No & $2,780(86.8)$ & 1 & - \\
\hline Yes & $420(13.2)$ & 10.92 & $8.70-13.72$ \\
\hline \multicolumn{4}{|l|}{ Tobacco } \\
\hline No & $2,412(75.3)$ & 1 & - \\
\hline Yes & $788(24.7)$ & 3.73 & $2.31-4.64$ \\
\hline \multicolumn{4}{|l|}{ Chewing habit duration } \\
\hline No & $1,884(58.8)$ & 1 & - \\
\hline$\leq 20$ years & $180(5.7)$ & 2.75 & $1.65-4.62$ \\
\hline$>20$ years & $1,136(35.5)$ & 4.89 & $1.28-6.89$ \\
\hline \multicolumn{4}{|l|}{ Chewing time } \\
\hline No & $1,884(58.8)$ & 1 & - \\
\hline$\leq 20$ minutes & $1,048(32.8)$ & 2.06 & $1.39-2.81$ \\
\hline$>20$ minutes & $268(8.4)$ & 5.17 & $3.02-7.72$ \\
\hline \multicolumn{4}{|l|}{ Chewing frequency } \\
\hline No & $1,884(58.8)$ & 1 & - \\
\hline$\leq 10$ times/day & $1,144(35.8)$ & 2.73 & $1.18-2.30$ \\
\hline$>10$ times/day & $172(5.4)$ & 3.08 & $1.16-6.42$ \\
\hline \multicolumn{4}{|l|}{ Smoking } \\
\hline No & $2,796(87.4)$ & 1 & - \\
\hline Yes & 404 (12.6) & 2.77 & $2.19-3.51$ \\
\hline \multicolumn{4}{|l|}{ Smoking frequency } \\
\hline No & $2,796(87.4)$ & 1 & - \\
\hline$\leq 10$ times/day & $328(10.2)$ & 2.64 & $2.04-3.42$ \\
\hline$>10$ times/day & $76(2.4)$ & 6.04 & $3.54-10.30$ \\
\hline \multicolumn{4}{|l|}{ Smoking duration } \\
\hline No & $2,796(87.4)$ & 1 & - \\
\hline$\leq 20$ years & $282(8.8)$ & 2.67 & $2.02-3.53$ \\
\hline$>20$ years & $122(3.8)$ & 3.87 & $2.61-5.74$ \\
\hline
\end{tabular}

Statistical significance, $\mathrm{p}<0.20$; OR: Crude odds ratio; $95 \%$ CI: $95 \%$ confidence interval
Table 3. Multivariate Logistic Regression Model of Risk Factors for OC and OPMDs

\begin{tabular}{lll}
\hline Variables/ Categories & $\mathrm{OR}^{\mathrm{a}}$ & $95 \% \mathrm{CI}$ \\
\hline $\begin{array}{l}\text { Age in years } \\
\quad<30\end{array}$ & 1 & - \\
$30-45$ & 3.66 & $1.59-8.46$ \\
$\quad>45$ & 3.5 & $2.18-5.63$ \\
Sex & & \\
$\quad$ Female & 1 & - \\
$\quad$ Male & 2.24 & $1.51-3.32$
\end{tabular}

Chewing habit

$\begin{array}{lll}\text { No } & 1 & - \\ \text { Arecanut } & 0.05 & 0.02-0.13 \\ \text { Tobacco } & 5.77 & 3.44-9.69\end{array}$

Arecanut

$\begin{array}{lll}\text { No } & 1 & - \\ \text { Yes } & 3.75 & 2.45-5.98\end{array}$

Commercial tobacco preparation

$\begin{array}{lll}\text { No } & 1 & - \\ \text { Yes } & 0.26 & 0.16-0.42\end{array}$

Chewing frequency

$\begin{array}{lll}\text { No } & 1 & - \\ \leq 10 \text { times/day } & 0.24 & 0.15-0.40 \\ >10 \text { times/day } & 0.31 & 0.15-0.65\end{array}$

Smoking

No

Yes

1

$0.14 \quad 0.05-0.39$

Smoking frequency

$\begin{array}{lll}\text { No } & 1 & - \\ \leq 10 \text { times/day } & 0.26 & 0.10-0.71 \\ >10 \text { times/day } & 0.69 & 0.18-0.97\end{array}$

Smoking duration

$\begin{array}{lll}\text { No } & 1 & - \\ \leq 20 \text { years } & 0.15 & 0.06-0.40 \\ >20 \text { years } & 0.42 & 0.08-0.84\end{array}$

Oral hygiene

$\begin{array}{lll}\text { Good } & 1 & - \\ \text { Fair } & 3.16 & 2.12-4.38\end{array}$

$\begin{array}{lrr}\text { Poor } & 8.07 & 3.51-13.16\end{array}$

Statistical significance, $\mathrm{p}<0.05$; OR: Adjusted odds ratio; $95 \% \mathrm{CI}, 95 \%$ confidence interval

alcohol. Squamous cell carcinoma was seen among 52 patients and remaining had verrucous carcinoma. Buccal mucosa/vestibule was the most affected site followed by floor of the mouth. On Simplified Oral Hygiene Index (OHIS), 52.6\% had fair oral hygiene and one third of the people had poor oral hygiene.

In order to assess the risk factors for OC and OPMDs, logistic analysis was carried out. The analysis shows association of OC and OPMDs with demographic characteristics, alcohol habits, and oral health conditions (Table 1). Logistic analyses were carried out for those parameters which were selected after sensitivity analysis. 
Odds ratio was $>1$ for variables like chewing areca nut, tobacco, commercial preparation and smoking (Table 2). Multivariate logistic analyses (Table 3 ) showed that disease risk increased with increase in frequency and duration of substance use and also with length of chewing of substance. Odds of disease occurrence increased with poor oral hygiene.

\section{Discussion}

Most of the people in the study were Hindu by religion and were farmer (semi-skilled) by profession. These data are consistent with the National Population and Housing Survey 2011 (Government of Nepal, 2011) and a study by Shrestha (2013). Almost 80\% were married and more than $80 \%$ could read and/or write. The literacy rates differed from the National Report where the literacy rate of EDR is $67.1 \%$ (Government of Nepal, 2012). This difference in the data could be because the question asked in our study questionnaire was "Are you able to read? Are you able to write?" and had no question about the education of an individual.

More than $40 \%$ of the population chewed either areca nut and/or tobacco. Eighteen percent were smokers and less than $10 \%$ consumed some form of alcohol. National sample survey on tobacco use (Government of Nepal, 2011) showed prevalence rate of overall smoking and tobacco use as $38.4 \%$ and $44.7 \%$, respectively. In our study, chewing tobacco was almost double of smoking. Similar result was found in a Global Adult Tobacco Survey (GATS) 2009-2010 in India where ratio of smokeless to smoking tobacco was 2:1 (International Institute for Population Sciences, 2010). The findings regarding presence of stains, periodontitis and OHI-S imply poor oral health awareness among the population surveyed.

A study (Oakley et al., 2005) done on high school children in Micronesia detected oral leukoplakia in 13\% and OSF in $8.8 \%$ followed by chewers mucosa and lichenoid reaction. In another hospital based study by Mathew et al., (2008) on 1190 patients, showed prevalence of OSF $(2.1 \%)$, smokers palate $2.77 \%$, betel and chewers mucosa $0.84 \%$ respectively. The variation in incidence of different OPMDs can be attributed to geographic location, lifestyle, frequency and duration of use of tobacco and alcohol products as well as the site of placement of smokeless tobacco products.

Gupta et al., (2014) reported an increased incidence of oral squamous cell carcinoma and verrucous carcinomas in patients chewing tobacco. Sawyer and Wood (1992) also reported an increased risk with increase in the frequency and duration of the habit. Though the nicotine content of chewing tobacco is much lesser than that in the smoking form, it is said to have more carcinogenic potential because it remains in contact with the oral mucosa for longer time. Tobacco-specific N-nitrosamines is present in higher concentrations in smokeless tobacco and the absorption is further enhanced in alkaline environments. These factors are known to influence the formation and levels of toxic chemicals in tobacco chewers and smokers which play a key role in the malignant transformation in the oral cavity. Among other factors which could modify the risk of oral lesions, alcohol appeared to increase the risk of OSF, leukoplakia, and lichen planus but not OC. Our findings are consistent with the finding of these studies (Gupta et al, 2014; Sawyer and Wood, 1992).

Our study involves population of EDR only hence, cannot be generalized to remaining part of the country. Further study with larger sample size including the nationwide data would provide true prevalence of these diseases in the country.

There is high prevalence of OC and/or OPMDs in the study population. Chewing areca nut, tobacco, commercial areca nut/tobacco preparation and smoking are the major risk factors for OPMDs and OC. Areca nut chewing with or without tobacco consumption emerged as the strongest risk factor for OPMDs and OC. Oral hygiene was also strongly associated with these oral diseases. The high prevalence of TPK and OSF in substance abusers compared with the general population emphasized the need for oral examination on a routine basis. Similar study is needed to document such findings of population in other parts of the country. Our research is a milestone in the epidemiology of OPMDs and OC, which would pave a path to plan the Oral Health Policy and implement oral health programs focused in the community of the target districts.

\section{Funding Statement}

The research was funded by University Grant Commission, Nepal under faculty research grant 068/069.

\section{Acknowledgements}

All the volunteers from local clubs/organizations who assisted in coordinating and organizing screening camps.

\section{References}

Balasimha D, Rajagopal V (2004). Arecanut monograph. In 'Alternative uses of arecanut and utilization of by products', Eds Annamalai SJK, Azeez S, Nayar NM. Central Plantation Crops Research Institute, Kerala, pp 224-39.

Government of Nepal, National Population and Housing Census 2011 (2012). Government of Nepal, National Planning Commission Secretariat, Central Bureau of Statistics, Kathmandu, pp 226.

Government of Nepal, Ministry of Health and Population (2011). The National Anti-tobacco Communication Campaign Strategy for Nepal. Kathmandu: Government of Nepal, Ministry of Health and Population. www.mohp.gov.np/ english/files/new_publications/9-3-Tobacco-Control-Act. pdf.

Gupta PC, Warnakulasuriya S (2002). Global epidemiology of areca nut usage. Addict Biol, 7, 77-83.

Gupta S, Singh R, Gupta OP, Tripathi A (2014). Prevalence of oral cancer and pre-cancerous lesions and the association with numerous risk factors in North India: A hospital based study. Natl J Maxillofac Surg, 5, 142-8.

International Institute for Population Sciences, Ministry of Health and Family Welfare (2010). Global Adult Tobacco Survey India (GATS India), 2009-10. Mumbai: International Institute for Population Sciences; New Delhi: Government of India, Ministry of Health and Family Welfare. www.searo. who.int/tobacco/documents/2010-pub2.pdf. 
Kerr AR, Warnakulasuriya S, Mighell AJ, et al (2011). A systematic review of medical interventions for oral submucous fibrosis and future research opportunities. Oral Dis, 17, 42-57.

Madani AH, Jahromi AS, Dikshit M, Bhaduri D (2010). Risk assessment of tobacco types and oral cancer. $\mathrm{Am} \mathrm{J}$ Pharmacol Toxicol, 5, 9-13.

Mathew AL, Pai K, Sholapurkar AA, Vengal M (2008). The prevalence of oral lesions in patients visiting a dental school in Southern India. Indian J Dent Res, 19, 99-103.

Oakley E, Demaine L, Warnakulasuriya S (2005). Areca (betel) nut chewing habit among high-school children in the Commonwealth of the Northern Mariana Islands (Micronesia). Bull World Health Organ, 83, 656-60.

Rimal J, Shrestha A (2015). Validation of Nepalese oral health impact profile14 and assessment of its impact in patients with oral submucous fibrosis in Nepal. J Nepal Health Res Counc, 13, 43-9.

Sawyer DR, Wood NK (1992). Oral cancer: Etiology, recognition and management. Dent Clin North Am, 36, 919-44.

Shrestha A, Rimal J, Singh SB, Khanal VK (2013). Oral health and tobacco issues among the people of Garamani village in eastern Nepal. $J$ Nepal Dent Assoc, 13, 1-5.

Williams M, Elwood M, Hislop G, et al (2008). Guideline for the early detection of oral cancer in British Columbia. Clinical Practice Guideline. J Can Dent Assoc, 74, 245.

Yang YH, Ho PS, Lu HM, Huang IY, Chen CH (2010). Comparing dose-response measurements of oral habits on oral leukoplakia and oral submucous fibrosis from a community screening program. J Oral Pathol Med, 39, 306-12.

Zini A, Czerninski R, Sgan-Cohen HD (2010). Oral cancer over four decades: epidemiology, trends, histology, and survival by anatomical sites. J Oral Pathol Med, 39, 299-305.

\section{Qब๑}

This work is licensed under a Creative Commons AttributionNon Commercial 4.0 International License. 